\title{
Familiares de Pessoas Diagnosticadas com Transtornos Alimentares: Participação em Atendimento Grupal
}

\author{
Laura Vilela e Souza ${ }^{1}$ \\ Universidade Federal do Triângulo Mineiro \\ Manoel Antônio dos Santos \\ Universidade de São Paulo
}

\begin{abstract}
RESUMO - O discurso biomédico com foco no diagnóstico frequentemente tem sido utilizado como recurso exclusivo para informar a assistência aos familiares de pessoas diagnosticadas com anorexia nervosa e bulimia nervosa. Este estudo buscou compreender como essas famílias constroem justificativas para participação em um grupo de apoio no contexto de tratamento dos transtornos alimentares. Uma sessão desse grupo, que abordava a temática de nosso interesse, foi analisada com apoio do discurso construcionista social. A análise empreendida destacou os sentidos coproduzidos sobre a ausência de alguns familiares no grupo, a diminuição de frequência de participação dos pais, a função desse grupo no tratamento, a periodicidade ideal de participação da família e a possibilidade de familiares e coordenadores do grupo coconstruírem o espaço conversacional.
\end{abstract}

Palavras-chave: Construcionismo Social; família; transtornos alimentares; grupo de apoio; grupo multifamiliar.

\section{Family Members of Persons Diagnosed with Eating Disorders: Participation in a Group Setting}

\begin{abstract}
The biomedical discourse focused on diagnosis has often been used as an exclusive alternative to inform treatment modalities for families of patients with anorexia nervosa and bulimia nervosa. This study aims to increase the understanding of how these families build justifications for their participation in a family support group in the eating disorder treatment context. Social constructionist discourse was used to analyze a session of the group in which the topic of our interest was addressed. The analysis highlighted co-produced meanings about the absence of some families in the group, the decrease of frequency of parent participation, the function of the group, the ideal frequency of family members, and the possibility of family members and coordinators co-construct the group conversational setting.
\end{abstract}

Keywords: Social Constructionism; family; eating disorders; support group; multifamiliar group.

No final do século XIX, o médico Gull (1874), considerado um dos descobridores da anorexia nervosa (AN), argumentava sobre a influência negativa da família no cuidado aos pacientes diagnosticados com esse transtorno. Até meados de 1960 é possível encontrar na literatura estudos que indicam a exclusão da família do tratamento como medida terapêutica (Harper, 1983). Preconizava-se afastar a pessoa acometida de seu núcleo familiar. A partir dessa época, mudanças importantes aconteceram na produção de sentidos sobre o lugar da família no tratamento dos transtornos alimentares (TA) (Souza \& Santos, 2007).

Em 2006, a American Psychiatric Association lançou um manual sobre o tratamento de pacientes com TA (APA, 2006). Considerando o estado da arte nessa área, os autores desse manual apontaram a importância da inclusão da família no tratamento, uma vez que os estudos que focalizam as propostas de intervenção que têm como base atendimentos familiares evidenciaram melhores indicadores de melhora dos sintomas dos pacientes. Por essa razão, esse manual apregoa que a participação da família no tratamento dos TA

1 Endereço para correspondência: UFTM, Universidade Federal do Triângulo Mineiro. Instituto de Educação, Letras, Artes, Ciências Humanas e Sociais. Avenida Getúlio Guaritá, 159, Centro Educacional Sala 320, Abadia. Uberaba, MG. CEP 38025-440. E-mail: lauravilelasouza@gmail.com é fundamental. De modo particular, os resultados positivos dessa participação seriam ainda mais evidentes no cuidado aos adolescentes diagnosticados com AN. O National Institute of Clinical Excellence (NICE), na Inglaterra, também enfatizou, em seu manual dedicado ao atendimento em TA (NICE, 2004), a importância da inclusão da família como estratégia de tratamento de pacientes de todas as idades. Le Grange, Crosby, Rathouz e Leventhal (2007) também apontaram como a participação dos pais ${ }^{2}$ pode ser benéfica e contribuir para a melhora dos sintomas dos pacientes diagnosticados com bulimia nervosa (BN).

Nesses estudos a inclusão da família no tratamento acontece, muitas vezes, para que ela seja alvo de intervenções terapêuticas, ou seja, parte-se do pressuposto de que a família deve ser tratada, considerando-se a dinâmica familiar como um dos fatores etiológicos dos TA(Dare, Eisler, Russell \& Szmukler, 1990). Essa forma de posicionar a família no tratamento tem sido questionada por pesquisadores contemporâneos que criticam a ideia de que essas famílias seriam homogêneas com relação a seus padrões interacionais (Eisler, 2005; Eisler et al., 2000; Le Grange \& Eisler, 2008; Roijen, 1992).

2 O termo "pais" será utilizado neste estudo para se referir a pais e mães, enquanto que o termo "filhos" será empregado para designar filhos e filhas. 
Um outro argumento passou a ser defendido, que é o da dinâmica familiar como possível mantenedora dos sintomas dos TA em seus membros considerados adoecidos (Schmidt $\&$ Treasure, 2006). Dessa forma, a proposta de intervenções com a família teria como objetivo investigar de que forma os familiares contribuem para com essa manutenção do TA e propor mudanças, especialmente na forma dos pais lidarem com seus filhos. Nesse sentido, a família passa a ser considerada não como fonte do problema, mas como fonte de potencial recurso de ajuda aos pacientes (Le Grange \& Eisler, 2008). Seguindo esses pressupostos, Lock, Le Grange e Agras (2001) estruturaram um modelo de atendimento para adolescentes com AN que buscava evitar movimentos de culpabilização da família e que entendia os pais como aliados e parceiros dos profissionais na condução do tratamento. Seguindo essas mesmas premissas, Le Grange e Lock (2007) propuseram um manual semelhante para o tratamento de adolescentes com BN. Alguns pesquisadores reivindicam o Family-Based Treatment (FBT), ou seja, o tratamento baseado nas intervenções da terapia familiar, como o de maior sucesso, considerando parâmetros como recuperação de peso como indicador de êxito (Chen et al., 2010; Couturier, Isserlin \& Lock, 2010; Lock, 2010).

Outra forma de entender a participação dos familiares no tratamento é considerar a sobrecarga emocional que as famílias vivenciam ao terem, entre seus membros, uma pessoa que apresenta uma psicopatologia tão grave (Sepulveda et al., 2010; Treasure, 2010). Nessa perspectiva, grupos de apoio, grupos de orientação ou grupos multifamiliares são propostos como estratégias que poderiam favorecer o apoio mútuo entre os familiares (Pasold, Boateng \& Portilla, 2010), a troca de experiências sobre modos eficazes de enfrentamento da doença (Bighetti, Santos \& Ribeiro, 2006) e orientações com relação a como os pais podem modificar seus comportamentos, de modo a prevenir o aparecimento dos TA (Loth, Neumark-Sztainer \& Croll, 2009).

Grupos de apoio psicológico têm sido oferecidos aos familiares como parte do atendimento ambulatorial (Souza $\&$ Santos, 2006). Contudo, poucos estudos foram realizados com o objetivo de investigar essa modalidade de atendimento familiar. Esse espaço conversacional, de modo geral, visa a oferecer apoio para as famílias, ajudando-as a lidar com seus familiares adoecidos, o que inclui a oferta de orientações sobre o que são os TA e possíveis estratégias para a melhora dos sintomas (Pasold, Boateng \& Portilla, 2010; Santos et al., 2002; Souza \& Santos, 2009). Nesse caso, assim como nas modalidades de atendimento mencionadas anteriormente, a participação da família acontece e se justifica em função do discurso hegemônico do diagnóstico.

Olhando para as mudanças paradigmáticas na maneira de entender a participação da família no tratamento dos TA, alguns pontos podem ser levantados quando consideramos as teorias sobre a etiologia desses transtornos e as propostas de tratamento delas decorrentes como construções sociais (Hepworth, 1999; Souza \& Santos, 2010). O discurso biomédico convida à exploração das relações das pessoas com sua alimentação em termos da diferenciação entre normalidade e patologia, sendo que AN e BN são construídas como entidades nosológicas. Esse é o discurso dominante que baliza a maior parte das propos- tas de assistência em TA no campo da saúde, legitimando intervenções que buscam identificar esses transtornos por meio da semiologia e da definição de estratégias para sua extinção. A partir da inteligibilidade conferida por esse discurso, uma proposta de tratamento eficaz seria aquela que lograsse oferecer a superação da psicopatologia por meio da remissão de seus sintomas. Todavia, quando saúde e doença são entendidas como construções sociais, tal como proposto pelo discurso construcionista social, outras possibilidades de produção de sentidos sobre a relação das pessoas com a alimentação, sobre o que será considerado sofrimento e sua possível superação, podem ser exploradas.

No discurso construcionista social, a pesquisa tem como foco principal o estudo do modo como as pessoas constroem sentidos em suas trocas linguísticas. Sendo assim, sentido é concebido como uma construção dialógica (Spink, 2000). Ou seja, os relacionamentos humanos geram linguagem e entendimento, em um processo não individual, contínuo, contextual, dinâmico e complexo (Gergen, 1997). Inspirado no discurso construcionista social, este estudo buscou compreender como os familiares das pessoas atendidas por um serviço de assistência em TA constroem justificativas para sua participação em um grupo de apoio psicológico.

\section{Método}

\section{Participantes da Sessão Selecionada}

Alessandra: psicóloga, coordenadora do grupo; Marcelo: psicólogo, coordenador do grupo; Monalisa: do lar, 45 anos, filha de 18 anos com diagnóstico de BN; Moisés: aposentado, 65 anos, filha de 16 anos com diagnóstico de AN; Isaura: aposentada, 55 anos, esposa de Moisés; Vilma: aposentada, 61 anos, filha de 42 anos com diagnóstico de AN; Matilde: do lar, 52 anos, filha de 25 anos com diagnóstico de AN; Miriam: funcionária pública, 47 anos, filha de 20 anos com diagnóstico de $\mathrm{BN}$.

\section{Procedimento}

Como parte das estratégias de coleta de dados de um projeto de pesquisa mais amplo, foram audiogravadas e transcritas na íntegra, por um período de seis meses, as sessões de um grupo de apoio psicológico para familiares de pessoas diagnosticadas com AN e BN de um serviço especializado, oferecido no contexto de um hospital universitário. Dentre os objetivos desse projeto maior, interessava conhecer como as famílias entendiam o convite para participarem dessa modalidade de atendimento.

$\mathrm{Na}$ época da coleta de dados, esse grupo era coordenado por dois psicólogos (um homem e uma mulher). Com frequência semanal, tinha uma hora de duração e era frequentado, em média, por seis participantes por sessão. Todos os familiares eram convidados a participarem e não existiam regras com relação à periodicidade de participação. Alguns familiares participavam semanalmente, outros apenas nos 
retornos ambulatoriais de seus parentes adoecidos (que podiam acontecer com intervalo temporal variado) e outros nunca haviam aceitado o convite para frequentar o grupo.

O objetivo desse grupo era oferecer um espaço de escuta e de trocas entre seus participantes, buscando incentivar o apoio mútuo. Via de regra, o grupo acontecia com base nos assuntos que emergiam espontaneamente das falas dos familiares. A partir de uma postura construcionista social (Anderson, 2009), que se afasta de descrições essencialistas sobre o mundo e as pessoas, e valoriza a diversidade de sentidos, os coordenadores buscavam posicionar a família como especialista na construção da melhora e entendiam a função da coordenação como a de facilitadora dessas conversas.

Em uma análise preliminar do conjunto de sessões grupais coletadas (um total de 24 sessões), que constituíram o corpus de pesquisa, foram destacados os temas que animaram as conversações em cada encontro. Com esse destaque, foi possível perceber que o tema da participação do familiar no grupo de apoio estava presente em grande parte das sessões (mais exatamente, em 16), todavia, em apenas uma delas tal temática foi dominante e constituiu pauta de conversa entre todos os familiares presentes. A participação da família no grupo foi o tema disparador das conversas em razão de um convite dos coordenadores do grupo, elaborado especialmente no contexto dessa sessão, para que os familiares manifestassem sua opinião sobre uma sugestão feita por um participante do encontro grupal anterior. A sugestão era que se enviasse uma carta, escrita pelas famílias participantes do grupo de apoio, endereçada aos familiares que nunca haviam participado do grupo ou que já não o frequentavam havia certo tempo. No encontro em apreço, ao conversarem sobre a possibilidade de uma escrita conjunta dessa carta-convite, os participantes se engajaram ativamente na tarefa de coconstrução de sentidos sobre o porquê a família deveria frequentar o grupo e quais seriam as vantagens e possibilidades em jogo nessa modalidade de participação no grupo, mas tal temática não era o foco principal do diálogo. Por essa razão, optou-se pela análise pormenorizada da sessão da carta-convite.

\section{Análise das Conversações}

A análise da sessão selecionada teve como primeiro foco, considerando-se o objetivo do estudo, os diferentes sentidos coproduzidos sobre a participação da família no grupo. Sucessivas leituras foram realizadas para o destaque desses sentidos nas falas dos coordenadores e dos participantes. Tornou-se importante, em seguida, entender como esses sentidos participavam da construção de direitos e deveres em relação a quem deveria participar do grupo e como deveria ser essa participação. Um conceito que favoreceu essa análise foi o dos jogos de posicionamentos. Esse conceito refere-se à "construção discursiva de histórias pessoais que fazem as ações das pessoas inteligíveis e relativamente determinadas como atos sociais e dentro das quais os participantes da conversa têm posições específicas" (Van Langenhove \& Harré, 1999, p. 16). Buscou-se entender como os coordenadores e familiares se posicionavam ou posicionavam uns aos outros e a terceiros em suas interações.
A cada sentido destacado na sessão, procurou-se, em seguida, compreender os jogos de posicionamentos implicados. Por fim, esses sentidos e posicionamentos foram colocados em diálogo com a literatura da área, buscando promover sua discussão. No presente estudo são apresentados, na ordem que apareceram na conversa, os conteúdos-chave que foram abordados na sessão, de modo a garantir sua contextualização.

Para permitir ao leitor o conhecimento do percurso argumentativo empreendido nessa análise, foram sublinhados os trechos das falas dos participantes a partir dos quais os sentidos sobre a participação grupal foram ressaltados. Essas falas são aqui apresentadas em fragmentos, sendo que em cada segmento de conversa um trecho foi sublinhado, com o destaque, logo em seguida, do respectivo sentido construído sobre a participação grupal. Uma exceção foi aberta para a apresentação de trechos da sessão que não remetiam a sentidos específicos sobre a participação grupal, mas que foram considerados úteis para a contextualização da dinâmica interacional. Outra estratégia de visualização utilizada na análise dos trechos de sessão grupal foi o destaque em itálico dos jogos de posicionamentos empreendidos. As palavras entre aspas utilizadas na discussão remetem aos termos utilizados pelos participantes do grupo.

Vale lembrar que, no discurso construcionista social, o pesquisador é parte do processo de produção de sentidos. Ou seja, os sentidos aqui destacados foram produzidos na interação pesquisador-material de análise. Outros sentidos poderiam ser problematizados a partir de outros diálogos em pesquisa.

Os pesquisadores obtiveram a concordância da coordenação do serviço no qual o estudo foi realizado e o projeto foi aprovado pelo Comitê de Ética em Pesquisa com Seres Humanos da instituição hospitalar. Todos os participantes formalizaram sua anuência assinando o Termo de Consentimento Livre e Esclarecido (TCLE) e tiveram seus nomes substituídos por pseudônimos.

\section{Resultados e Discussão}

A sessão iniciou-se com o coordenador Marcelo retomando o encontro da semana anterior, no qual os participantes questionaram a ausência de alguns familiares:

Marcelo: Gente, na semana passada... a Matilde estava aqui, Vilma estava aqui. E nós conversamos um pouco sobre esse grupo. E uma das coisas que nós percebemos era que cada vez mais tava ficando, tava ficando cada vez mais difícil de alguns pais virem pra cá, tanto que esse grupo, que às vezes era muito grande, vinha muita gente, às vezes vem só uma pessoa. Isso tem acontecido.

Um primeiro sentido sobre o espaço grupal pôde ser construído a partir dessa primeira fala de Marcelo, a saber, "o grupo" como um local que foi se tornando "difícil" de frequentar. Na literatura da área, como visto na introdução deste estudo, um grupo de apoio psicológico, no contexto do tratamento dos TA, funcionaria como um espaço de oferecimento de apoio mútuo para que os familiares pudessem 
lidar com a sobrecarga de ter um membro adoecido em sua família (Pasold, Boateng \& Portilha, 2010; Souza \& Santos, 2009). Sendo assim, a baixa frequência de participantes nesse grupo seria sinônimo da impossibilidade de oferta desse tipo de apoio às famílias assistidas pelo serviço especializado. A partir desse sentido, os coordenadores do grupo ficariam posicionados como aqueles que deveriam ajudar os participantes presentes a pensarem em estratégias para incrementar essa participação.

E uma das idéias, né, que surgiu na semana passada, foi de escrever uma carta para os pais, né? Uma carta pra esses pais que não tão vindo ãh... pra dizer algumas coisas e convidá-los pra estarem aqui presentes, né?

Com a ideia de uma carta-convite, dois subgrupos se formaram entre os familiares das pessoas atendidas pelo serviço, posicionando-os como os pais que frequentam o grupo e os pais ausentes. Interessante notar que, ainda que esse grupo tenha sido proposto para atender a todos os familiares das pessoas com TA, incluindo pais, irmãos, irmãs, namorados, maridos e esposas, na narrativa de Marcelo o grupo foi descrito em termos da necessidade da participação dos pais, daí a proposta de uma carta escrita aos pais ausentes. Esse sentido para a participação grupal pode ter relação com a presença maciça de pais nesse grupo e a exclusividade dessa categoria na sessão aqui selecionada para análise. Marcelo prosseguiu sua explanação:

E ai eu acho que a proposta do grupo de hoje é essa, da gente pensar um pouco nesse grupo e tentar juntos aqui escrever uma carta pra quem não tá vindo, né? Pra esses pais que não tão vindo. Mas eu acho que pra isso a gente precisa pensar no grupo, na gente, comentar como é que estão as coisas aqui.

No convite para conversarem sobre o próprio grupo, Marcelo talvez buscasse produzir o efeito de que os familiares fizessem sua avaliação sobre o esvaziamento do grupo. $\mathrm{O}$ sentido é do grupo como um espaço para se avaliar o próprio grupo, em sua estrutura e funcionamento. Nessa construção, os familiares foram posicionados como corresponsáveis pelo funcionamento grupal, tanto em sua capacidade de tecer avaliações sobre o grupo, como de tomar decisões sobre como sanar possíveis dificuldades encontradas em sua participação. Essa forma de posicionar os familiares no grupo é inteligível a partir das teorias sobre grupo que defendem a horizontalidade na relação profissional-cliente (Rasera \& Japur, 2001). Além disso, constrata com a opinião dos primeiros profissionais que buscaram tratar os TA e que julgavam com desconfiança qualquer opinião emitida pela família (Harper, 1983). Essa abertura oferecida à família é própria dos modelos contemporâneos de atenção em saúde, que pensam a família como parceira no tratamento (Lock, Le Grange \& Agras, 2001).

A primeira pessoa a responder ao convite de Marcelo foi Monalisa:

Monalisa: Então... assim, eu, toda semana eu não posso vir aqui, quem pode, né, toda semana não dá e nunca falta, né?
Ainda que o convite de Marcelo possa ter sido almejado quebrar tradicionais hierarquias existentes no relacionamento entre profissional e família, favorecendo com que os familiares ocupassem o mesmo lugar de tomada de decisão em que os coordenadores se encontravam, a resposta de Monalisa parecia articular outro sentido para a participação no grupo: o da obrigação de frequentá-lo toda semana. Ao justificar sua dificuldade em participar semanalmente, Monalisa posicionava os coordenadores como aqueles que se incumbiriam do gerenciamento da participação no grupo, colocando-os em um lugar de autoridade a quem se deveriam dar explicações. Essa postura encontra eco na tradição relacional em saúde, que vê o profissional como superior ao cliente em relação a tomada de decisões no tratamento (Souza \& Santos, 2009). Nessa construção relacional, a carta-convite tinha o sentido de chamar a atenção das pessoas ausentes e cobrar sua maior frequência no grupo.

Deve-se lembrar de que lugar os participantes respondem à proposta de Marcelo. O hospital, como cenário das práticas discursivas empreendidas, circunscreve algumas possibilidades de jogos de posicionamentos e privilegia, dada a tradição cultural vigente, o posicionamento do profissional como dono de um poder absoluto sobre as decisões no tratamento. Daí ser possível entender a necessidade dos participantes de se desculparem por suas faltas, dirigindo seus pedidos de desculpa aos coordenadores do grupo. Na sequência, Moisés teceu sua narrativa:

Moisés: Eu penso que as pessoas, cada um tem assim a sua própria situação, seus próprios limites, suas próprias dificuldades para de vez em quando não vir. É! Eu acho que cada um teve as suas razões.

A fala de Moisés pareceu dialogar com o sentido anteriormente atribuído à participação do grupo como obrigação. Em sua narrativa, outras justificativas para os pais ausentes foram apresentadas e a participação no grupo foi construída como algo que dependeria dos limites de cada família. Os pais foram posicionados como aqueles que deveriam avaliar esses limites, e não a coordenação do grupo. Essas construções falam da família como autônoma em sua decisão de participar ou não do grupo, em constraste com sentidos dispersos na literatura da área, que fixam um lugar para a família como organização fragilizada e adoecida, que necessita do julgamento dos profissionais para avaliar de que forma essa participação no tratamento deveria acontecer (Dare et al., 1990). Moisés, diferentemente de Monalisa, não se posicionou como alguém que deveria oferecer justificativas para suas ausências. Ele prosseguiu:

Mas praticamente chegamos à conclusão que as pessoas fazendo isso, de vir só de 15 em 15 dias, nós já achamos o suficiente, por vários motivos. O motivo principal poderia ser que a Beatriz, a nossa filha, está bem melhor.

Aqui construi-se outro sentido para a participação dos pais no grupo, que foi o da necessidade de engajamento no espaço grupal apenas quando o paciente (filho ou filha, no caso dos familiares presentes nesse encontro) não "está bem”. Desse modo, a participação dos pais seria justificada em função da 
gravidade dos sintomas do TA dos filhos, tal como apregoado por estudos da área (Dare et al., 1990; Schmidt \& Treasure, 2006). A partir desse sentido outorgado, não seria possível pensar outras funções do grupo que não estivessem ligadas ao discurso biomédico do diagnóstico do TA. Dessa forma, os pais de pacientes que não "estão bem" e que mesmo assim encontram-se ausentes do grupo são posicionados como negligentes com relação ao tratamento. O grupo, para além do discurso da doença, perderia seu propósito.

Na sequência dessa sessão, Isaura e Moisés mencionaram como era difícil comparecer toda semana devido aos gastos financeiros com transporte. Miriam contou que sempre pedia para o marido vir e ele não aceitava. Em resposta a esses esforços de justificação da ausência no grupo, Marcelo perguntou aos participantes se eles acharam, a partir de sua fala inicial, que ele estaria cobrando a presença dos participantes. Após Monalisa dizer que achava que não era cobrança, mas que a participação dos pais ajudava, Marcelo questionou no que essa presença ajudaria. Miriam respondeu:

Miriam: E eu tenho pedido pra ela [filha atendida no serviço] vir também. Saber que a gente tá acompanhando não é importante? Eu acho! Porque ela [filha] fica muito contente quando eu venho. E quando falo que não posso, eu vejo que ela fica meio frustrada. E ela queria que eu estivesse toda semana. Eu acho.

Na fala de Miriam, o sentido oferecido para a participação no grupo tinha relação com o bem-estar percebido pelo filho quando seus pais participavam do tratamento. Esse sentido parece falar não apenas da pessoa identificada como paciente, mas da própria família, entendida por alguns pesquisadores na área como fonte de recursos e apoio aos pacientes (Le Grange \& Eisler, 2008). Os pais ficam posicionados, a partir da fala de Miriam, como fonte de cuidado e não como alvo de intervenção. A família é vista como potente e não, necessariamente, como debilitada e adoecida.

Marcelo deu continuidade à conversa:

Marcelo: E pra você, Moisés? Você sentiu que era uma cobrança? Que tinha que vir toda semana?

Moisés: Não! É... eu penso assim, que... pensava igual ir lá, mas... não é assim necessário, vamos dizer assim. Mas a gente, assim, fica com uma dúvida, se não participar. Então, a gente decidiu por frequentar.

$\mathrm{Na}$ afirmação de Moisés, construiu-se a dúvida sobre qual seria a periodicidade ideal para os pais participarem dos encontros. Ou seja, o sentido de participação seria outorgado por não se saber se a ausência seria de algum modo nociva. Ainda que, em um primeiro momento, seja possível uma abertura para a família decidir a periodicidade de sua participação, os sentidos em saúde que legitimam a proposta desse atendimento grupal para os membros familiares circulam em um campo discursivo próprio dos profissionais em saúde, no qual os familiares não necessariamente têm acesso. Ou seja, os objetivos do grupo são pensados a partir dos discursos em saúde que legitimam o profissional como especialista. Sendo assim, é pertinente a dúvida de Moisés em relação à presença dos pais no grupo. A partir dessa lógica, a coordenação do grupo pode acabar posicionada como responsável pela indicação da frequência adequada da família no tratamento. O conhecimento trazido pela própria família pode ficar em segundo plano. Moisés emendou:

Agora, como já disse, já faz algum tempo, né, que a gente [ele e sua esposa] resolveu que ia vir só de 15 em 15 dias. É que achávamos mais razoável. Mais razoável, certo? [...] Mas talvez já não seja mais tão necessário nesse momento, como já estamos fazendo não vai modificar nada, nada.

Ao dizer que, atualmente, não era mais "tão necessária" sua participação (bem como de sua esposa), Moisés poderia estar falando de como a participação da família em um grupo de apoio psicológico está relacionada ao estado clínico do filho ou filha, ou seja, à sua resposta ao tratamento. Nessa perspectiva, o grupo seria percebido em função da psicopatologia (Souza \& Santos, 2009). A família, a partir desse sentido outorgado, pode ser posicionada como responsável por oferecer apoio ao paciente (Le Grange \& Eisler, 2008). Moisés prosseguiu sua narrativa:

Porque uma carta, mesmo bem feita, não ia mudar o pensamento da pessoa que não está a fim de vir. A pessoa que... está consciente, ãh... a pessoa que sente a necessidade de frequentar aqui para ajudar-se e ajudar os outros pais também, acho que não precisa de... Aliás, isso, vocês sempre falam aqui: "é bom vir!", quer dizer, uma pessoa assim não precisa de mais outro estímulo, extra-estímulo, digamos, uma carta para voltar a frequentar, não sei. Poderia acontecer, sim!

Nesse fragmento da narrativa de Moisés, o grupo é construído como um espaço para que os pais ofereçam e recebam ajuda. Essas construções dialogam com os sentidos, presentes na literatura da área de grupo como espaço para lidar com a sobrecarga emocional da doença (Sepulveda et al., 2010) ou como espaço de oferta de apoio mútuo (Pasold, Boateng \& Portilha, 2010; Santos et al., 2002). Os pais ausentes foram posicionados como aqueles que optam conscientemente por não participarem do grupo.

Em seguida, a coordenadora Alessandra pediu aos participantes que haviam comparecido à sessão anterior que explicassem aos demais sobre a proposta da carta. Vilma afirmou:

Vilma: É o seguinte. Foi assim. Tem muitas mães que chegam, elas vêm pra consulta, mas não vêm aqui no grupo. Às vezes as filhas não vão também no grupo [de pacientes]. Então, se elas vêm, se chegam no horário da consulta, por que não vir aqui, né? Que se aqueles que... você falou: "melhorou!".

Ao falar das mães que nunca participaram da reunião, Vilma ressaltou a participação no grupo em razão apenas da busca da melhora quando se está em um momento difícil. Esse sentido tem como efeitos: a ausência, no grupo, dos pais que estão com os filhos "melhores" e a impossibilidade de contarem aos demais pais como essa melhora foi possível, compartilhando seu conhecimento de modo a socializar possíveis estratégias exitosas. Perde-se, assim, a função do grupo de apoio como espaço de troca de experiências (Bighetti, Santos \& Ribeiro, 2006; Santos et al., 2002). Respondendo a esse sentido, Vilma apontou o que justificaria 
a necessidade de presença desses pais cujos filhos estariam em situação melhor:

Eu acho que o mais interessante é que aquele que teve melhora é que deveria vir, porque eu sinto assim com a minha filha, que já faz tantos anos, já passei por todas as situações possíveis, e eu ainda chego aqui com esperança. Se eu não tenho o grupo, hoje eu chego aqui e: "nossa! Eu vim, estou desanimada, eu não tenho estímulo mais! Eu tô triste! Angustiada!”, qualquer coisa, então, agora eu já tô me sentindo melhor, porque eu tô entre amigos, que durante todo o tempo eu tõ invocada com uma pessoa doente dentro de casa.

É o sentido do grupo como espaço no qual os pais, cujos filhos se encontram em melhor situação clínica, oferecem apoio para familiares que enfrentam situação mais difícil. O grupo, como espaço de intercâmbio e apoio mútuo independentemente da gravidade dos sintomas dos TA, poderia renovar a "esperança" de pais que, como Vilma, precisariam de "estímulo" para enfrentar a condição adoecida de seus filhos. Ao posicionar-se como alguém que enfrentava intenso sofrimento ao lidar com sua filha, Vilma posicionou, indiretamente, os pais ausentes como aqueles que se recusavam a oferecer tal apoio aos demais.

Parece ser em resposta a essa construção do TA como um quadro grave que Miriam sugeriu que a carta-convite contivesse uma explicação sobre o que é a doença:

Miriam: Eu falei, é uma carta-convite. Essa carta ia explicaro quê que é a doença, porque muita gente não sabe. Eu, quando vim [no grupo] no começo, eu levei a maior decepção da minha vida. Não sei se vocês se lembram como é que eu ficava no começo. Eu fiquei chocada. Nem sonhava, não fazia ideia dessa doença, do jeito que era, nada. Ai que eu fui ver a gravidade, nossa! Foi a mesma coisa que soltar uma pedra de paralelepípedo em cima da cabeça, no começo. Agora eu já consigo conversar. Eu não conseguia conversar. No começo, vocês podem ver que eu só queria ficar calada, eu queria só chorar!

Nesse fragmento narrativo, o grupo foi construído como espaço de conscientização da família sobre a existência e a gravidade da doença. Dessa forma, os coordenadores seriam aqueles que deveriam conduzir os membros do grupo para a tarefa de explicarem para as pessoas, como Miriam, que "não faziam ideia de nada", o conceito e a "gravidade da doença". Esse sentido legitima o discurso biomédico que entende a AN e a BN como fenômenos psicopatológicos (APA, 2006), com características e funcionamento específicos. Nessa concepção essencialista, não há espaço para a consideração dos múltiplos sentidos possíveis sobre a relação que a pessoa estabelece com a alimentação. O sentido de psicopatologia é privilegiado e naturalizado como o correto, e o conhecimento de tal "verdade", por parte do profissional da saúde especialista na área, deveria ser também compartilhado com as famílias (National Institute of Clinical Excellence, 2004). Esse sentido construído para o grupo teve como efeito, conforme conta Miriam, o seu silenciamento, uma vez que saber da "doença" a fez perceber sua própria ignorância em relação ao sofrimento que acometia sua filha.

Vilma se manifestou em seguida à fala de Miriam:
Vilma: Porque, às vezes a gente vê um caso no grupo, como é, assim, por muitos anos, você tentando, e fica assim receosa de falar algumas coisas e a pessoa que tá começando agora ficar chocada com tudo, né?

Um dos efeitos de Miriam ter contado como foi difícil ouvir no grupo de apoio sobre a gravidade do quadro da filha parece ter posicionado Vilma como alguém capaz de chocar os pais iniciantes no grupo ao contar das dificuldades que vive em relação à filha. Nesse momento, o diagnóstico de TA circunscreveu o grupo como um espaço no qual não era prudente falar da gravidade da doença para não "chocar" os pais iniciantes no tratamento. A possibilidade de troca ficou, portanto, limitada. Por outro lado, ao se tomar AN e BN como construções sociais, é possível colocar em discussão quais outros sentidos alternativos sobre a relação que os filhos desses familiares estabelecem com a alimentação poderiam ser evocados, de modo a evitar a desesperança que o diagnóstico de um transtorno crônico pode provocar.

Essa sequência de conversações pareceu convidar Isaura e Matilde a falarem de outros grupos de apoio, dos quais já haviam participado em razão de psicopatologias diagnosticadas em outros familiares. Foi construída, nessa conversação, a diferença entre TA e outras psicopatologias, sendo que os primeiros seriam menos graves do que, por exemplo, a esquizofrenia ou o transtorno bipolar. Considerando-se a dificuldade de manejo imposta pela "doença" e sua gravidade, o grupo foi construído como lugar de sofrimento dos pais. Participou da construção desse sentido o discurso em saúde, que valoriza o sofrimento emocional de familiares de pessoas portadoras de sofrimento mental (Treasure, 2010). Uma das consequências desse discurso é fomentar práticas de assistência aos familiares. Todavia, a família, como objeto de cuidado, pode ser tomada como frágil ou "desempoderada"; nesse contexto, os profissionais priorizariam suas próprias estratégias de atenção em saúde, sem a construção conjunta de ferramentas para se lidar, por exemplo, com as consequências do discurso diagnóstico de um TA.

Marcelo retomou a conversa sobre a carta-convite, indagando sobre como as pessoas gostariam de coordenar suas ações para escrevê-la. Vilma contou que, na sua experiência, quando convidava os pais que nunca haviam participado a irem ao grupo, eles simplesmente se recusavam. Por essa razão, e em resposta à pergunta de Marcelo sobre como redigir a carta, Vilma declarou que achava melhor que os coordenadores escrevessem a mensagem. A carta escrita pela coordenação pareceu ser uma proposta a favor do sentido do grupo como espaço no qual os coordenadores tiravam a família do seu suposto "não saber" sobre o que acontece com seus filhos, por meio da oferta de orientação e informação maciça aos pais. Nesse sentido, os coordenadores foram posicionados como aqueles que encarnavam a autoridade do grupo. Evitando endossar e naturalizar essa posição, Marcelo reiterou sua ideia de que a carta fosse resultado de algo que os próprios familiares acreditassem que era importante de ser dito para os pais ausentes. Moisés, então, voltou a se manifestar no grupo:

Moisés: Eu penso que, em geral, tem que ser completamente diferente, ãh... de uma carta do banco, né? [Risos]. Essa carta 
é armadilha! Indução, "você pode emprestar mais no banco, e tudo. Você que vai ganhar! Estamos pensando em você!’ Na verdade, estão pensando no bolso deles...

Isaura: $\dot{E}$.

Marcelo: Quer dizer, nós não estamos convidando as pessoas para uma armadilha.

Moisés: Não, né? Isso não pode.

Ao comparar a carta-convite com uma "carta de banco", Moisés propunha compreender a participação no grupo como algo que traria benefício primário ao próprio participante e não como um lucro a ser extraído em proveito de quem fazia o convite. Ou seja, não seria "uma armadilha" porque se acreditava que o ganho principal era do familiar que aceitasse frequentar o grupo. Ao mesmo tempo, a carta-convite, como uma lembrança dos presentes sobre a falta que esses pais estavam fazendo no grupo, aponta para o sentido do grupo como algo que é bom para quem dele participa, mas que também pode ser bom para os demais participantes. Só que, diferentemente da carta protocolar de um banco, não seria uma forma de enganar ou de tirar proveito da boa-fé do destinatário da mensagem.

Ao serem convidados pela coordenação a pensarem como poderiam falar, na carta, da falta que sentiam dos pais ausentes, alguns participantes retomaram as dificuldades para participar do grupo. Narrativas de desesperança em relação ao potencial da carta-convite podem ter levado o coordenador Marcelo a propor que os familiares presentes pensassem nas experiências anteriores, nas quais haviam sido convidados para algo e gostaram da forma como esse convite aconteceu. Essa fala do coordenador valorizava os recursos que os familiares possuíam sobre como fazer convites que não seriam recebidos como "armadilhas" e buscava posicioná-los como capazes de planejarem estratégias para fortalecer a participação das famílias nesse espaço reservado a elas. Essa postura do coordenador se aproxima da forma contemporânea de posicionar a família parceira no tratamento, conforme mencionado anteriormente, mantendo-a lado a lado com o profissional (Le Grange \& Lock, 2007).

Posicionados como capazes, os participantes começaram a oferecer ideias de como compor a carta e Moisés se ofereceu para rascunhá-la.

Marcelo: Isso! Vamo escrevendo as frases que o grupo tá falando, depois a gente costura umas nas outras. Pra depois fazermos uma carta mais organizada, mas agora vamos pensar nas frases que vocês gostariam de ouvir, se não estivessem aqui. A Isaura já falou: "como seria bom que você voltasse!". E o que mais? Isaura: Seria sobre a...? Pros pais...

Monalisa: Eu colocaria assim: "como seria bom se você voltasse. Sua presença me é muito importante!”.

Na sugestão de Monalisa, a participação do familiar no grupo foi construída a partir do bem que ele faria aos demais pais. Moisés suplementou esse sentido:

Moisés: É importante para vocês, mas também para nós!

Marcelo: Completa aí, então... Seria muito importante para você e para nós.

Moisés: Para você e para nós que estamos enfrentando...
Os familiares ausentes foram posicionados, na última fala de Moisés destacada nesse fragmento, como aqueles que não mais estariam "enfrentando" o problema e, portanto, iriam para o grupo para ofertar sua experiência de superação aos demais. Todavia, o grupo pensado como um espaço de trocas e apoio mútuo não caberia nessa descrição do familiar (que tinha um(a) filho(a) "melhor") participando apenas em função de seu potencial de ofertar ajuda. Assim, Moisés solucionou esse "problema" por meio da construção de sentido do grupo como importante também para o familiar que já enfrentou o problema, pois ele obteria ganhos e isso promoveria a troca e o enriquecimento mútuo. A possibilidade de significar a oferta de ajuda como uma situação que também traz ganhos para quem se dispõe a ajudar garantiria a participação dos pais que se encontravam em situação mais confortável.

Todos os participantes continuaram empenhados na redação da carta:

\section{Moisés: "Aqui temos a oportunidade de..." \\ Alguns [falando ao mesmo tempo]: "Aprender e ensinar!".}

A participação do familiar no grupo, definida em termos da aprendizagem que esse integrante poderia oferecer aos demais, contrasta com o sentido do grupo como espaço para que os coordenadores ensinassem aos familiares o que é a "doença" e como lidar com ela (Schmidt \& Treasure, 2006). No primeiro caso, os coordenadores seriam os facilitadores da conversa que teria como protagonistas os familiares, uma vez que estes foram posicionados como tendo domínio de um conhecimento válido sobre a vivência de seus filhos.

A conversa prosseguiu, e na sequência Isaura se colocou:

Isaura: Seria compartilhar!

Marcelo: Adiciona... "aprender, ensinar, compartilhar”, o quê? Isaura: Os nossos sentimentos, as nossas dores. É... as angústias...

Moisés: Em resumo...

Marcelo: A compartilhar...

Isaura: As angústias, os medos, as esperanças...

Marcelo: Angústias, medos, esperanças, o que mais que a gente divide aqui?

No intercâmbio dialógico, o grupo foi proposto como um compartilhar de "sentimentos", "dores" e "angústias". E quando Marcelo enfatizou que esses eram sentimentos "divididos" por todos, os familiares assistidos pelo serviço foram posicionados como iguais, podendo ter uma participação de importância equivalente no grupo. Ao mesmo tempo, o entendimento de tais famílias, configurado a partir de suas "dores" e "angústias", remete à construção da relação entre ter um membro diagnosticado com TA e a sobrecarga emocional dos familiares, como informam muitas das pesquisas na área (Pasold, Boateng \& Portilla, 2010; Sepulveda et al., 2010; Treasure, 2010). Essa forma de entendimento convida ao suporte mútuo e à identificação entre os participantes (Bighetti, Santos \& Ribeiro, 2006), mas também pode levar à construção de um sentido de homogeneidade dessas famílias, que impede que elas sejam vistas a partir de outros sentidos que valorizem a heterogeneidade nas formas de responder ao discurso do diagnóstico. 
Ao acrescentar a "esperança" entre os sentimentos compartilhados no grupo, Isaura pareceu estar respondendo a essa forma de significar o diagnóstico do TA como um evento grave e que envolve riscos físicos e até a possibilidade de morte, que são os sentidos majoritariamente apregoados pela literatura científica (APA, 2006), buscando enfatizar um movimento contrário, de expectativa de superação do problema e de retomada da condição de saúde. Importante considerar o lugar ocupado por Isaura nessa sessão grupal: o de mãe de uma filha que obteve sucesso no tratamento.

Em seguida, Marcelo perguntou:

Marcelo: Como é que a gente assinaria?

Moisés: Ah! Já terminou?

Alguns [falando ao mesmo tempo]: Não!

Marcelo: Que mais que você gostaria de...

Moisés: [Lê tudo o que escreveram até o momento em voz alta]:

"Como seria bom se você voltasse. Sua presença me é muito importante. Importante para nós também, que frequentamos essa grupo familiar. Aqui temos a oportunidade de aprender e ensinar, em resumo: de compartilhar as angústias, medos e esperanças. Sentimos a sua falta e gostaríamos de convidá-lo(a) a participar do grupo sem medo. Oferecemos a nossa ajuda e precisamos da sua!"

Monalisa: Tá quase completa!

Isaura: "Contamos com vocês!"

Marcelo: E aí, como é que a gente assinaria essa carta?

Monalisa: E se todos assinassem?

$\mathrm{Na}$ fala de Isaura, a carta se completaria com a explicitação, para os pais ausentes, de que os seus remetentes "contavam" com sua participação. A forma como os diálogos foram sendo desenhados ao longo da sessão, com o posicionamento dos pais presentes como autores da carta, em vez dos coordenados do grupo, permitiu que, ao término da tarefa, todos se sentissem responsáveis por sua assinatura.

Marcelo: Cada um escreveria o seu nome? Ainda que vocês não estejam lá terça-feira que vem, nós podemos pôr o nome de vocês...

Miriam: Eu acho que sim. Pode pôr.

Isaura: Eu acho!

Monalisa: Vocês assinam por mim se eu não estiver aqui.

O pedido de Monalisa, de que alguém pudesse garantir que seu nome fosse incluído mesmo em sua eventual ausência, e o fato de todos assinarem, tornou a carta fruto do trabalho conjunto feito pelas famílias. Porém, Vilma sugeriu um detalhe a mais:

Vilma: Tem que ter o timbre do hospital, porque senão não leva a sério.

Alessandra: Cê acha que tem que ter o timbre do hospital?

Alguns [falando ao mesmo tempo]: Ah! Eu acho! Senão nin-

guém... Precisa, né?

Moisés: Eu acho que não!

Miriam: A pessoa vai... vai achar que a gente que...

Marcelo: É trote? [Risos]

Miriam: Enrolou, isso!
Monalisa: A pessoa tem que sentir que foi o hospital que mandou a carta.

O hospital, como a instância legitimadora do tratamento, teve seu espaço garantido na carta, como forma de garantir a seriedade do convite, o que implica endossar a autoridade que emana do poder biomédico. Por outro lado, se na literatura da área os profissionais de saúde que gerenciam a instituição hospitalar são, muitas vezes, posicionados como especialistas na condução do tratamento e na decisão sobre de que forma a família deve participar desse processo, nesse momento foi a própria família quem definiu como o hospital iria participar de uma decisão que ela própria tomou sobre como deveria acontecer essa participação. Retomando o início do encontro grupal investigado, ao enfatizar a carta como uma ideia dos familiares para tentar sanar o problema da rarefação da frequência no grupo, e ao se propor a ouvir o que os familiares presentes pensavam tanto da situação vivida no grupo, como da proposta da carta-convite, o coordenador participou ativamente da construção da possibilidade da família ver-se como protagonista das decisões tomadas e favoreceu com que o hospital pudesse aparecer na carta, mas não meramente como uma autoridade distante e superior, mas como um parceiro da família, um apoio, como sublinhado por Monalisa.

\section{Considerações Finais}

O que sustenta a importância da presença da família no tratamento são as teorias científicas sobre $\mathrm{AN}$ e $\mathrm{BN}$ que garantem ao profissional o lugar de especialista sobre uma condição saudável, e da família ou como alvo de tratamento e orientação, ou como parceira no combate à condição que obstrui o caminho que conduz à saúde. Nessa lógica discursiva, a diminuição da frequência de participação no grupo pode ser um problema para os coordenadores, mas não é, necessariamente, para os participantes.

O convite para os participantes conversarem sobre o grupo abriu espaço para a problematização sobre em que medida era importante estar no grupo e para quem era importante essa presença. Todavia, cabe uma ressalva sobre a seguinte questão: de que lugar esses familiares estariam falando? Ainda que não sejam tomados como pacientes, o privilégio do profissional com relação às decisões do tratamento posiciona a família em um lugar de maior passividade. Nesse sentido, o profissional de saúde é chamado a realizar um movimento autorreflexivo e ético de ponderar em que medida suas teorias sobre o papel da família no tratamento, sobre o que torna o grupo de apoio um espaço efetivo e sobre a função que sua coordenação opera na produção de um atendimento eficaz, podem limitar suas ações e a exploração de outras configurações relacionais.

Em muitos momentos, os sentidos tecidos neste estudo reproduziram os discursos tradicionais em saúde que justificam a participação da família em grupo de apoio apenas em função do diagnóstico de TA. Essa reprodução apresenta-se como um limite quando se pensa no potencial que pesquisas futuras podem ter ao escolherem enfatizar sentidos alternativos, buscando as exceções às tradições. Outro limite deste estudo foi a impossibilidade de conhecer de que forma os 
pais ausentes entendem a participação no grupo de apoio. Pesquisas futuras com esse objetivo serão úteis para ampliar a compreensão sobre o potencial desse tipo de intervenção em saúde.

Um desafio posto aos profissionais é confiar nos recursos da família para prover cuidados aos pacientes diagnosticados com TA, oferecendo oportunidade para ela participar da condução do tratamento, da avaliação dos atendimentos disponíveis para os familiares e da estruturação de espaços compartilhados para o desenvolvimento de recursos. O discurso construcionista social propõe que, uma vez que não podemos fundamentar nossa prática profissional em verdades universais, devemos apostar em ações definidas com a colaboração de todas as pessoas envolvidas no cenário de sofrimento. Em outras palavras, o que vai ser considerado a melhor participação possível no tratamento só pode ser construído na parceria colaborativa e dialógica estabelecida entre pacientes, familiares e profissionais.

\section{Referências}

American Psychiatric Association (2006). Practice guideline for the treatment of patients with eating disorders. Washington, DC: American Psychiatric Association.

Anderson, H. (2009). Conversação, linguagem e possibilidades: Um enfoque pós-moderno da terapia. São Paulo: Roca.

Bighetti, F., Santos, J. E., \& Ribeiro, R. P. P. (2006). Grupo de orientação clínico-nutricional a familiares de portadores de transtornos alimentares: Uma experiência "GRATA". Medicina (Ribeirão Preto), 39, 410-414.

Chen, E. Y., Le Grange, D., Doyle, A. C., Zaitsoff, S., Doyle, P., Roehrig, J. P., \& Washington, B. (2010). A case series of familybased therapy for weight restoration in young adults with anorexia nervosa. Journal of Contemporary Psychotherapy, 40, 219-224.

Couturier, J., Isserlin, L., \& Lock, J. (2010). Family-based treatment for adolescents with anorexia nervosa: A dissemination study. Eating Disorders, 18, 199-209.

Dare, C., Eisler, I., Russell, G. F. M., \& Szmukler, G. I. (1990). The clinical and theoretical impact of a controlled trial of family therapy in anorexia nervosa. Journal of Marital \& Family Therapy, 16, 39-57.

Eisler, I. (2005). The empirical and theoretical base of family therapy and multiple family day therapy for adolescent anorexia nervosa. Journal of Family Therapy, 27, 104-131.

Eisler, I., Dare, C., Hodes, M., Russell, G., Dodge, E., \& Le Grange, D. (2000). Family therapy for adolescent anorexia nervosa: The results of a controlled comparison of two family interventions. Journal of Child Psychology and Psychiatry, 41, 727-736.

Gergen, K. J. (1997). Realities and relationships: Soundings in social construction (2nd ed). Cambridge: Harvard University Press.

Gull, W. (1874). Anorexia nervosa (apepsia hysteria, anorexia hysteria). Transactions of the Clinical Society of London, 7, 222-228.

Harper, G. (1983). Varieties of parenting failure in anorexia nervosa: Protection and parentectomy revisited. Journal of American Academy of Child Adolescent Psychiatry, 22, 134-139.
Hepworth, J. (1999). The social construction of anorexia nervosa. London: Sage.

Le Grange, D., Crosby, R. D., Rathouz, P. J., \& Leventhal, B. L. (2007). A randomized controlled comparison of family-based treatment and supportive psychotherapy for adolescent Bulimia Nervosa. Archives of General Psychiatry, 64, 1049-1056.

Le Grange, D., \& Eisler, I. (2008). Family interventions in adolescent Anorexia Nervosa. Child and Adolescent Psychiatric Clinics of North America, 18, 159-173.

Le Grange, D., \& Lock, J. (2007). Treating bulimia in adolescents: A family-based approach. New York: Guilford Press.

Lock, J. (2010). Treatment of adolescent eating disorders: Progress and challenges. Minerva Psychiatry, 51 (3), 207-216.

Lock, J., Le Grange, D., \& Agras, W. S. (2001). Treatment manual for anorexia nervosa. London: The Guilford Press.

Loth, K. A., Neumark-Sztainer, D., \& Croll, J. K. (2009). Informing family approaches to eating disorder prevention: Perspectives of those who have been there. International Journal of Eating Disorders, 42, 146-152.

National Institute of Clinical Excellence. (2004). National clinical practice guideline: Core interventions in the treatment and management of anorexia nervosa, bulimia nervosa, and related eating disorders. London: National Institute for Clinical Excellence.

Pasold, T., Boateng, B., \& Portilla, M. (2010). The use of a parent support group in the outpatient treatment of children and adolescents with eating disorders. Eating Disorders, 18, 318-332.

Rasera, E. F., \& Japur, M. (2001). Contribuições do pensamento construcionista para o estudo da prática grupal. Psicologia: Reflexão e Crítica, 14, 201-209.

Roijen, S. (1992). Anorexia nervosa families: A homogeneous group? A case record study. Acta Psychiatric Scandinavian, $85,196-200$.

Santos, R. K., Mouraria, C. G., Soares, I. V. B., Prizanteli, C. C., Bighetti, F., Godoy, R. S. P., Ribeiro, R. P. P., \& Santos, M. A. (2002). Grupo de apoio psicológico aos familiares de portadores de anorexia e bulimia nervosa. Revista da SPAGESP, 3, 139-143.

Schmidt, U., \& Treasure, J. (2006). Anorexia nervosa: Valued and visable: A cognitive interpersonal maintenance model and its implications for research and practice. British Journal of Clinical Psychology, 45, 343-366.

Sepulveda, A. R., Todd, G., Whitaker, W., Grover, M., Stahl, D., \& Treasure, J. (2010). Expressed emotion in relatives of patients with eating disorders following skills training program. International Journal of Eating Disorders, 43, 603-610.

Souza, L. V., \& Santos, M. A. (2006). A família e os transtornos alimentares. Medicina (Ribeirão Preto), 39, 403-409.

Souza, L. V., \& Santos, M. A. (2007). Anorexia e bulimia: Conversando com as famílias. São Paulo: Vetor.

Souza, L. V., \& Santos, M. A. (2009). A construção social de um grupo multifamiliar no tratamento dos transtornos alimentares. Psicologia: Reflexão e Crítica, 22, 483-492.

Souza, L. V., \& Santos, M. A. (2010). A participação da família no tratamento dos transtornos alimentares. Psicologia em Estudo, 15, 285-294.

Spink, M. J. P. (2000). Práticas discursivas e produção de sentidos no cotidiano: Aproximações teóricas e metodológicas. São Paulo: Cortez. 
Treasure, J. (2010). How do families cope when a relative has an eating disorder? In J. Treasure, S. Ulrike, \& P. MacDonald (Eds.), The clinician's guide to collaborative caring in eating disorders: The new Maudsley method (pp. 45-59). New York: Routledge/Taylor \& Francis Group.

Van Langenhove, L., \& Harré, R. (1999). Introducing positioning theory. In R. Harré, \& L. Van Langenhove (Eds.), Positioning theory (pp. 14-31). Oxford: Blackwell Publishers.

Recebido em 16.09.2010

Primeira decisão editorial em 18.05.2011

Versão final em 16.01.2012

Aceito em 30.01.2012

\section{MUDANÇA DE ENDEREÇO}

Se você está mudando de endereço, por favor, notifique Psicologia: Teoria e Pesquisa. Ocasionalmente, assinantes e autores comunicam tardiamente mudança de endereço gerando dificuldades na entrega de nossa revista ou de outras correspondências. Informe imediatamente, se possível com antecedência, qualquer mudança de domicílio para:

Universidade de Brasília - Instituto de Psicologia

Revista Psicologia: Teoria e Pesquisa

Secretaria de Divulgação

70910-900 Brasília DF

Mudanças de endereço poderão também ser comunicadas através do correio eletrônico revptp@unb.br, telefone 5561 31076826 e fax 556131076892 . 